The Harvard Kennedy School Misinformation Review1

May 2020, Volume 1, Special Issue on COVID-19 and Misinformation

Attribution 4.0 International (CC BY 4.0)

Reprints and permissions: misinforeview@hks.harvard.edu

DOI: https://doi.org/10.37016/mr-2020-023

Website: misinforeview.hks.harvard.edu

\title{
Feeling "disinformed" lowers compliance with COVID-19 guidelines: Evidence from the US, UK, Netherlands and Germany
}

This study indicates that, during the first phase of the coronavirus (SARS-CoV-2) pandemic in 2020, citizens from the US, UK, Netherlands, and Germany experienced relatively high levels of mis- and disinformation in their general information environment. We asked respondents to indicate the extent to which they experienced that general information on the new coronavirus (SARS-CoV-2 and the disease it causes, COVID-19) was erroneous or inaccurate (misinformation) or intentionally misleading (disinformation). Those who experienced misinformation were willing to seek further information and to comply with official guidelines. Individuals perceiving more disinformation - on the other hand - were less willing to seek additional information and reported lower willingness to comply with official guidelines.

Authors: Michael Hameleers (1), Toni G. L. A. van der Meer (2), Anna Brosius (3)

Affiliations: $(1,2,3)$ Amsterdam School of Communication Research, University of Amsterdam

How to cite: Hameleers, M.; van der Meer, T. G. L. A., Brosius, A. (2020). Feeling "disinformed" lowers compliance with

COVID-19 guidelines: Evidence from the US, UK, Netherlands and Germany, The Harvard Kennedy School (HKS)

Misinformation Review, Special Issue on COVID-19 and Misinformation

Received: April 14th, 2020 Accepted: May 28th, 2020 Published: May 31st, 2020.

\section{Research questions}

- RQ1: To what extent do people perceive general information on COVID-19 as erroneous and intentionally misleading?

- RQ2: Are people with stronger mis- and disinformation perceptions on COVID-19 more or less willing to comply with official guidelines, such as social distancing?

- RQ3: Do people's perceptions of information on COVID-19 as disinformation vs. misinformation predict their willingness to comply with official guidelines in different ways?

- RQ4: Do people's perceptions of information on COVID-19 as disinformation vs. misinformation motivate their information consumption patterns in different ways?

\section{Essay summary}

- In a survey among a diverse sample of Dutch, German, U.S., and U.K. citizens ( $N=1,321)$, we asked respondents to indicate the extent to which they experienced that general information on the new coronavirus, SARS-CoV-2 and the disease it causes, COVID-19, was erroneous or inaccurate (misinformation) or intentionally misleading (disinformation).

1 A publication of the Shorenstein Center on Media, Politics and Public Policy at Harvard University's John F. Kennedy School of Government. 
- We found that people with stronger misinformation perceptions (i.e., they reported that erroneous information on COVID-19 prevailed) were more willing to comply with official guidelines and search more actively for novel information.

- People with stronger disinformation perceptions (i.e., they reported that deceptive and intentionally false information on COVID-19 prevailed) are generally less willing to comply and tend to actively avoid news on the new coronavirus and COVID-19, albeit this effect is most pronounced in the UK.

- These findings have real-world implications: Misinformation perceptions might stimulate prosocial behavior. Healthy skepticism and awareness of the presence of erroneous information might motivate the search for additional information, potentially without undermining trust in authorities. People with disinformation perceptions, in contrast, are likely to avoid news and less willing to follow instructions of the authorities (i.e., social distancing, washing hands frequently).

- Our key suggestion for official information sources, in particular governments, the WHO, and journalists, is to increase the public's trust in their intentions to inform truthfully and help citizens to distinguish honest mistakes (misinformation) from intentionally deceptive content (disinformation).

\section{Implications}

The coronavirus pandemic in 2020 may be one of the worst global crises of the past decades. The first phase of the COVID-19 outbreak was characterized by a lack of certainty and a heightened sense of emergency. As indicated by media dependence theory, in times of crisis, citizens rely heavily on the news media to inform them in a truthful and honest way about novel developments (Boukes et al., 2019). The type of news being spread amongst citizens can be crucial in the (de-)escalation of a public-health crisis (Liu \& Kim, 2011).

This reliance on news and general information during health crises comes with large challenges; in particular, the spread of misinformation. Previous research has documented the omnipresence of misinformation in the context of infectious disease outbreaks about, for example, potential cures (Oyeyemi et al., 2014) or vaccine development (Drezde et al., 2016). Oyeyemi et al. (2014) showed how most tweets and retweets about the Ebola outbreak contained misinformation. Kleis Nielsen et al. (2020) show that, in the context of the recent coronavirus pandemic, a high number of citizens in different countries report that they came across false or misleading information about COVID-19, in particular on social media platforms and messaging apps. While less common, some respondents also have concerns about governments and news organizations spreading mis- and disinformation (see Kleis Nielsen et al., 2020). Certain types of inaccurate crisis information can confuse individuals and make them less likely to protect themselves, which, in turn, can exacerbate the spread of the pandemic (Van der Meer \& Jin, 2019; Tan et al., 2015). For this reason, it is important to consider the extent to which citizens perceive information on the new coronavirus and the disease it causes as erroneous and/or intentionally misleading (RQ1). Here, it is important to note that we look at perceptions of false information related to all aspects of the 2020 health crisis: It pertains to perceived false information on the virus (SARS-CoV-2), the disease it causes (COVID-19), the treatment of the virus and the disease, and other information related to the consequences, origins, and treatment of the pandemic in general.

It is important to understand how perceptions of the presence of inaccurate information inform behavior (or intentions to act), such as compliance with official guidelines to avoid the spread of the virus - e.g., keeping physical distance, or washing one's hands (RQ2). On the one hand, health-related misinformation could result in public indifference or distrust, which could impede citizens from taking 
recommended actions (Tan et al., 2015). On the other hand, when people perceive there is a lot of inaccurate information about the new coronavirus and COVID-19, they may be more concerned about being misinformed and compensate by turning to health expert sources, which in turn might increase their willingness to comply with public-health measures.

Differences in compliance could be explained by previous findings that different types of inaccurate information perceptions may have dissimilar (political) consequences (e.g., Freelon \& Wells, 2020; Wardle, 2017; Tandoc Jr. et al., 2018). Here, we make a distinction between misinformation and disinformation. Misinformation is defined as any type of inaccurate information that is spread without the intention to mislead (but may still cause harm without the disseminators' knowledge) (e.g., Wardle, 2017). It may be argued that the dissemination of misinformation is a necessary consequence of high levels of uncertainty and conflicting evidence during the first weeks of the pandemic: Knowledge and empirical evidence was lacking, and experts disagreed as they did not have all the facts. Disinformation, however, refers to false or misleading information intentionally designed and spread to cause public harm (e.g., Freelon \& Wells, 2020). Beliefs of misinformation, i.e., perceptions of 'honest mistakes' in uncertain times, may not undermine trust in the independence and honesty of (expert) information channels as much as beliefs of disinformation, i.e., perceptions of intentional deception. Media trust is an important factor here as it is associated with higher levels of compliance with pandemic-containment measures (H1N1 outbreak; Prati et al, 2011). Moreover, especially when inaccurate information downplays the severity of the crisis, which is often the case for disinformation, people could be less likely to follow expert recommendations - e.g., during Hurricane Florence, residents refused to evacuate because the effects were perceived as less severe by the public than they actually were (Sandman et al., 2005). Ergo, people with stronger disinformation perceptions about the new coronavirus and COVID-19 might be less willing to comply with the official guidelines in place than people with misinformation perceptions - we therefore explore to which extent mis- and disinformation inform compliance in similar or different ways (RQ3).

In addition, perceptions of mis- and disinformation may inform individuals' approach or avoidance of news on the new coronavirus and COVID-19 in different ways (RQ4). Information seeking is an important outcome, as it can, for example, predict vaccine uptake (Lin et al. 2013). When people perceive information as intentionally misleading and dishonest (disinformation), they may be more likely to avoid any information on the pandemic. However, people that perceive that information contains honest mistakes' (misinformation) may actually look for more information and verify claims to reduce uncertainty (Berger \& Calabrese, 1975; Boyle et al., 2004). Even though people with similar perceptions of mis- and disinformation and information approach/avoidance behaviors can have different motivations for believing why information is false and/or misleading, it can be argued that the general distinction between unintentional versus intentional falsehoods is the most decisive factor in motivating information search: If people distrust the honesty and neutrality of sources, they may avoid news on the coronavirus. However, if they believe that information is factually wrong without the intention to deceive, they may simply approach more information to triangulate sources, or critically assess the evidence and arguments put forward - which can help them to contextualize honest mistakes.

In the present study, we rely on survey data collected in Germany, the Netherlands, the UK and the USA during the first weeks of the pandemic outbreak $(N=1,312)$. Data were collected within 24 hours on March 19th, 2020. At this point, the outbreak in these countries was not as severe as in, for example, Italy or Spain, but there was a lot of uncertainty regarding the spread of the virus and the measure that governments would implement.

Overall, during this phase, respondents believed that mis- and disinformation were salient phenomena but were significantly more likely to classify information on the new coronavirus and COVID-19 as misinformation than disinformation. We also found that these perceptions predict compliance, news seeking and avoidance in opposite ways: people with more pronounced misinformation perceptions are more likely to comply (i.e., social distancing, stay at home, strict hygiene measures) and actively find new 
information on the virus and the disease it causes, whereas people with disinformation perceptions are less likely to comply and more likely to actively avoid information.

These findings have important implications. Misinformation perceptions may be associated with behaviors that are conducive to the fight against the pandemic: people with such perceptions engage more in information seeking and comply more with interventions that can help to combat the coronavirus. Disinformation perceptions, in contrast, may promote less pro-social behavior, and could result in noncompliance and avoidance of crucial information in times of crisis. As the distinction between mis- and disinformation can be difficult to make by the audience in times of high uncertainty, it is important to help news consumers recognize the difference between honest mistakes and deception. In line with these implications, we forward two specific recommendations: (1) official sources should restore and maintain trust in their neutrality and honesty and (2) media literacy should be stimulated.

First, it is crucial that official sources of information (in particular independent health organizations, and news media disseminating the information of these sources) convince the audience of their neutrality and honesty, especially in the initial phase of a crisis outbreak. Official sources can acknowledge that there is uncertainty and a lack of clear information and emphasize that they rely on impartial expert knowledge - and that they have no intentions to mislead. This may reduce the perception that information sources are purposefully lying or hiding facts. Our findings indicate that perceiving a lack of factual knowledge (misinformation) is not problematic, but that restoring and maintaining trust in the intentions of communicators is crucial (disinformation).

Second, it is important to stimulate media literacy (Tully, Vraga \& Bode, 2019). Governments can, for example, design public service announcements in which they offer suggestions on how to recognize misand disinformation and recommend sources of verified expert knowledge. In addition, professional journalists can make the distinction between mis- and disinformation central when they verify information. This could help citizens understand when information is contradictory because of a lack of reliable information, and when contradictions originate from intentional deception.

\section{Findings}

Finding 1: People associate general information on the new coronavirus and COVID-19 with mis- and disinformation, but are more likely to perceive information as misinformation (honest mistakes) than disinformation (intentionally misleading).

Figure 1 shows the mean scores of mis- and disinformation perceptions related to the pandemic for all four countries. The findings indicate that, overall, people believe that information on the virus and COVID-19 is surrounded by mis- and disinformation to a relatively large extent: on a 7-point scale, the average level of misinformation is $4.88(S D=1.34)$. The average level of disinformation is $4.46(S D=$ 1.41). Yet, participants distinguish misinformation (honest mistakes) from disinformation (deliberate deception): across all countries, people perceive that there is significantly less intentionally misleading information than simply incorrect information. There are a few noteworthy country differences. The Netherlands score lowest on perceived mis- and disinformation, whereas participants in the UK and US score considerably higher on these perceptions. In these two countries, the difference between misinformation and disinformation perceptions is slightly stronger compared to Germany and the Netherlands. 


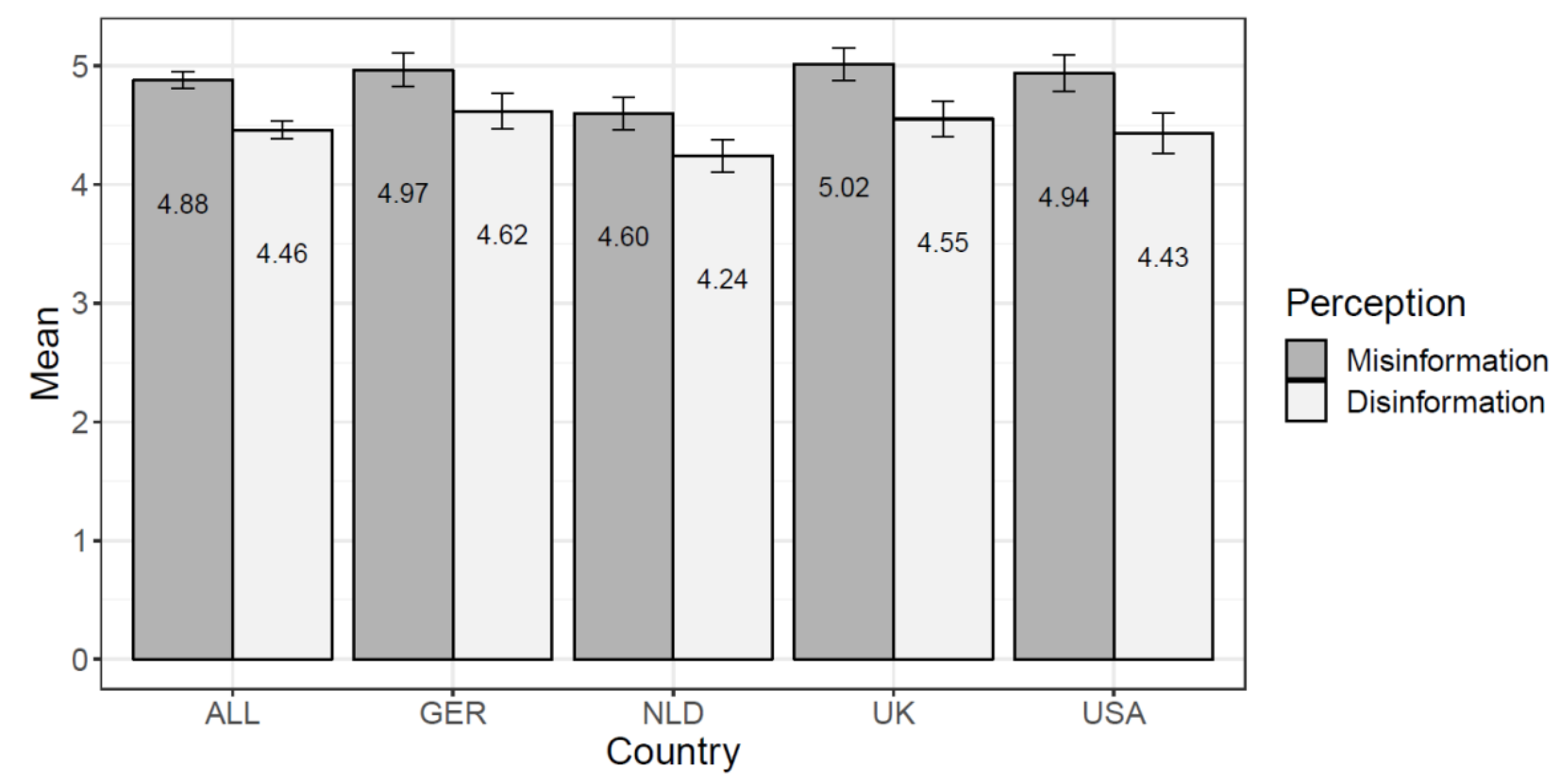

Figure 1. Mean score comparison of mis- and disinformation perceptions related to COVID-19 and SARS-CoV-2 across countries. Individual items were measured on 7-point disagree-agree scales.

We showed that people overall have more pronounced mis- than disinformation perceptions. Next, we explore how these perceptions can be distinguished based on their relationship with compliance and information-seeking behavior.

Finding 2: People with stronger misinformation perceptions are more likely to comply with interventions to combat the new coronavirus and COVID-19, whereas people with stronger disinformation perceptions are less willing to comply.

For all results reported, we control for factors and perceptions that can predict mis- and disinformation perceptions and the dependent variables of interest. Among others, these include: being infected with the virus or knowing people who are affected, perceived implications of the virus for people's economic situation, education, and ideological self-placement (measures included in Appendix A).

In response to $\mathrm{RQ} 2$ and $\mathrm{RQ} 3$, Table 1 shows that participants with more pronounced misinformation perceptions are more willing to comply with governmental interventions than people with less pronounced misinformation perceptions. However, people with stronger disinformation perceptions are less willing to comply with governmental interventions. Accordingly, an additional variable measuring whether respondents held a stronger disinformation perception compared to a misinformation perception, showed a negative association with intention to comply with public-health measures among people with a stronger perception of disinformation compared to misinformation (see Appendix C).

As Appendix B shows, these findings are mirrored in most national settings. Yet, disinformation perceptions only significantly correspond to less willingness to comply in the UK, whereas this correspondence is non-significant in the other countries. In sum, we found that people with stronger misinformation perceptions are more willing to comply with interventions, whereas disinformation may impede willingness to comply with interventions in some contexts.

Finding 3: People with stronger disinformation perceptions tend to actively avoid corona-related information, whereas people with more pronounced misinformation perceptions tend to approach corona-related news. 
We showed that, even though disinformation perceptions are less pronounced than misinformation beliefs, believing that information is intentionally misleading or dishonest could, in some cases, correspond to less compliance. Responding to RQ4, we additionally find that participants with stronger disinformation perceptions are more likely to actively avoid information on the new coronavirus and COVID-19, whereas those with more pronounced misinformation perceptions actively search for information on the crisis (see estimates in Table 1). Perceptions of mis- and disinformation thus differently predict the approach and avoidance of novel information on the outbreak. The findings are backed up by analyses that show how respondents who hold a stronger disinformation perception than a misinformation perception (dichotomous variable) are more likely to avoid coronavirus- and COVID-19 related news and less likely to seek additional information (see Appendix C).

Again, these patterns hold across different national settings (see Appendix B), although we find that people with stronger misinformation perceptions in the US and the UK are more likely to intentionally approach news on the virus and COVID-19, whereas this is not significant in Germany and the Netherlands. However, participants with stronger disinformation perceptions across all four national settings are more likely to actively avoid COVID-19-related news than participants with less pronounced disinformation perceptions.

Table 1. Willingness to comply, news avoidance, and intentional exposure among participants at higher levels of perceived mis- and disinformation

\begin{tabular}{|c|c|c|c|}
\hline & Compliance & News avoidance & Information seeking \\
\hline Misinformation & $0.27^{* * *}(0.03)$ & $-0.09^{\dagger}(0.05)$ & $0.20^{* * *}(0.05)$ \\
\hline Disinformation & $-0.07^{*}(0.03)$ & $0.27^{* * *}(0.05)$ & $-0.14^{* *}(0.05)$ \\
\hline Gender (male) & $-0.35^{* * *}(0.07)$ & -0.09 (0.09) & $0.12(0.10)$ \\
\hline Age & $-0.00(0.00)$ & $-0.00^{*}(0.00)$ & $0.00(0.00)$ \\
\hline Left-right ideology & $0.01(0.01)$ & $0.06^{* *}(0.02)$ & $-0.03(0.02)$ \\
\hline Education & $0.10^{*}(0.04)$ & $-0.02(0.06)$ & $0.17^{*}(0.07)$ \\
\hline $\begin{array}{l}\text { COVID-19 infection } \\
\text { (expecting } \\
\text { contamination) }\end{array}$ & $0.81(0.53)$ & $-0.52(0.77)$ & $0.77(0.82)$ \\
\hline $\begin{array}{l}\text { COVID-19 infection } \\
\text { (expecting no }_{\text {contamination) }^{\mathrm{a}}}\end{array}$ & $0.84(0.52)$ & $-0.28(0.75)$ & $0.40(0.80)$ \\
\hline $\begin{array}{l}\text { COVID-19 (prefer not } \\
\text { to answer) }\end{array}$ & $0.10(0.54)$ & $0.21(0.78)$ & $-0.36(0.84)$ \\
\hline $\begin{array}{l}\text { Knows Others infected } \\
\text { (No) }{ }^{b}\end{array}$ & $-0.05(0.12)$ & $-0.25(0.17)$ & $0.05(0.18)$ \\
\hline $\begin{array}{l}\text { Knows Others infected } \\
\text { (prefer not to } \\
\text { answer) }\end{array}$ & $-1.15^{* * *}(0.30)$ & $-0.35(0.44)$ & $-0.62(0.47)$ \\
\hline $\begin{array}{l}\text { Income affected by } \\
\text { crisis }\end{array}$ & $-0.00(0.00)$ & $0.00^{*}(0.00)$ & $0.00(0.00)$ \\
\hline Country (US) & $-0.22^{*}(0.09)$ & $0.14(0.13)$ & $0.17(0.14)$ \\
\hline
\end{tabular}




\begin{tabular}{llll}
\hline Country $(\mathrm{UK})^{\mathrm{c}}$ & $-0.04(0.09)$ & $0.25^{\dagger}(0.13)$ & $0.04(0.14)$ \\
Country $(\mathrm{GER})^{\mathrm{c}}$ & $0.22^{*}(0.09)$ & $-0.11(0.13)$ & $0.70^{* * *}(0.14)$ \\
& & & \\
Constant & $4.09^{* * *}(0.54)$ & $1.81^{*}(0.79)$ & $3.66^{* * *}(0.85)$ \\
$N$ & 1,321 & 1,321 & 1,321 \\
\hline
\end{tabular}

Note. Cells contain unstandardized regression coefficients, standard errors in parentheses

$+p<0.10, * p<0.05, * * p<0.01, * * * p<0.001$

a reference category: I was tested positive for corona

${ }^{b}$ reference category: Others I know are infected by corona

${ }^{c}$ reference category: The Netherlands

In sum, in the initial phase of the COVID-19 pandemic, people perceived that information on the coronavirus is to a relatively large extent surrounded by misinformation, and, to a lesser extent, disinformation. Perceptions of misinformation positively motivate compliance with public-health regulations (i.e., physical distancing, staying at home as much as possible) and further information seeking. However, despite disinformation perceptions being less prominent than misinformation perception, they could be harmful as they are associated with less compliance and avoiding coronarelated information in some contexts.

\section{Methods}

We collected survey data $(N=1,321)$ among participants in the US, UK, Netherlands, and Germany (sample distributions approach national representativeness on core demographics). We fielded the survey on March 19 1 th 2020 and closed the fieldwork within 24 hours after the launch of the survey to make sure that the impact of fast-moving real-world developments is minimal. The sampling was conducted by an international research company (Dynata), recruiting participants from mixed panel sources. Only participants that passed a basic attention check were included in the final analyses. The results are similar when all participants are included (30.65\% failed the attention check, these participants do not differ from participants retained in the analyses). The interview was computerassisted: people answered questions in an online format programmed in Qualtrics. In Appendix A, we provide an in-depth description of the demographic and sample composition for each country.

First, we measured perceptions of misinformation on the new coronavirus and COVID-19 with two items $(M=4.88, S D=1.34)$. Disinformation perceptions were measured with two other items $(M=4.46$, $S D=1.41$, item wordings in Appendix A). Although the scales are strongly correlated, CFA analyses indicate that perceptions of mis- and disinformation form separate scales with acceptable convergent and discriminant validity. The overall fit of the two-dimensional model is satisfactory: $\chi^{2}(1)=8.84, \chi^{2} / \mathrm{df}$ $=8.84, p=.003 ; \mathrm{RMSEA}=0.05,90 \% \mathrm{Cl}[0.03,0.09] ; \mathrm{CFI}=.99, \mathrm{TLI}=.99$. The standardized regression weights demonstrate that all factor loadings are good indicators of the underlying latent construct. The correlation between the two factors is high (.72), but discriminant validity of the model is acceptable (merging the two dimensions results in a substantially and significantly worse model fit $\left(\Delta \chi^{2}(1)=398.42\right.$, $p<0.001$ ).

Next to measures of mis- and disinformation perceptions, we included measures of compliance with official guidelines $(M=5.88, S D=1.22)$, the seeking $(M=4.97, S D=1.79)$ and avoidance $(M=2.65, S D=$ 1.77) of news on the new coronavirus and COVID-19, and a number of control variables related to compliance, news selection, and avoidance (see Appendix A for details on the measurement of all items). 
Running this survey in four countries simultaneously in a short period of time allows us to answer our research questions on the extent to which participants experience the presence of mis- and disinformation in their news environment, and to what extent different levels of these perceptions correspond with people's self-reported willingness to comply with governmental interventions.

Perceptions of mis- and disinformation may change over the course of the pandemic. Uncertainty and conflicting evidence may have been reduced over time, compared to the initial phase of the outbreak which we analyzed. It is also important to note that our findings cannot be generalized to countries that were not part of the sample, as different degrees of crisis severity, different interventions, and different media systems could impact the relationship we investigate. Although we collected samples that reflect the population in terms of age and gender, we measured perceptions of mis- and disinformation among people that are part of research panels and therefore may differ from the overall population on a number of unmeasured factors. The data we collected is cross-sectional, relying on self-reported measures that are correlated, which means that we cannot make causal inferences about whether misor disinformation perceptions predict compliance or vice versa. Yet, our data allows us to better understand news consumers' perceptions of the (in)accuracy and (dis)honesty of news and general information, and how these perceptions predict their willingness to comply with governmental interventions.

\section{Bibliography}

Bennett, L. W. \& Livingston, S. (2018). The disinformation order: Disruptive communication and the decline of democratic institutions. European Journal of Communication. doi:10.1177/0267323118760317

Berger, C. R., \& Calabrese, R. J. (1975). Some explorations in initial interaction and beyond: Toward a developmental theory of interpersonal communication. Human Communication Research, 1(2), 99-112. https://doi.org/10.1111/j.1468-2958.1975.tb00258.x

Boukes, M., Damstra, A., \& Vliegenthart, R. (2019). Media effects across time and subject: How news coverage affects two out of four attributes of consumer confidence. Communication Research. doi:10.1177/0093650219870087

Boyle, M. P., Schmierbach, M., Armstrong, C. L., McLeod, D. M., Shah, D. V., \& Pan, Z. (2004). Information Seeking and Emotional Reactions to the September 11 Terrorist Attacks. Journalism \& Mass Communication Quarterly, 81(1), 155-167. https://doi.org/10.1177/107769900408100111

Dredze, M., Broniatowski, D. A., \& Hilyard, K. M. (2016). Zika vaccine misperceptions: A social media analysis. Vaccine, 34, 3441-3442.

Freelon, D. \& Wells, C. (2020). Disinformation as political communication. Political Communication, 37(2), 145-156. doi:10.1080/10584609.2020.1723755

Kleis Nielsen, R., Fletcher, R., Newman, N., Brennen, J. S., \& Howard, P. N. (2020, April 15th). Navigating the 'infodemic': how people in six countries access and rate news and information about coronavirus. Reuters Institute for the Study of Journalism

Lin, L., Savoia, E., Agboola, F., \& Viswanath, K. (2014). What have we learned about communication inequalities during the H1N1 pandemic: A systematic review of the literature. BMC Public Health, 14(1), 484. https://doi.org/10.1186/1471-2458-14-484

Liu, B. F., \& Kim, S. (2011). How organizations framed the 2009 H1N1 pandemic via social and traditional media: Implications for US health communicators. Public Relations Review, 37, 233-244. doi:10.1016/j. pubrev.2011.03.005 
Marwick, A., \& Lewis, R. (2017). Media manipulation and disinformation online (pp. 1-104). Data and Society Research Institute. Retrieved September 18, 2018, from https://datasociety.net/output/media-manipulation-and-disinfo-online/

Oyeyemi, S. O., Gabarron, E., \& Wynn, R. (2014). Ebola, Twitter, and misinformation: A dangerous combination? BMJ, 349, g6178. doi:10.1136/bmj.g6178

Prati, G., Pietrantoni, L., \& Zani, B. (2011). Compliance with recommendations for pandemic influenza H1N1 2009: The role of trust and personal beliefs. Health Education Research, 26(5), 761-769. https://doi.org/10.1093/her/cyr035

Quinn, S. C., Parmer, J., Freimuth, V. S., Hilyard, K. M., Musa, D., \& Him, K. H. (2013). Exploring Communication, Trust in Government, and Vaccination Intention Later in the 2009 H1N1 Pandemic: Results of a National Survey. Biosecurity and Bioterrorism: Biodefense Strategy, Practice, and Science, 11(2), 96-106.

Reynolds, B., \& Quinn, S. C. (2008). Effective Communication During an Influenza Pandemic: The Value of Using a Crisis and Emergency Risk Communication Framework. Health Promotion Practice, 9(4_suppl), 13S-17S. https://doi.org/10.1177/1524839908325267

Sandman, P., \& Lanard, J. (2005). Tsunami risk communication: Warnings and the myth of panic. In Emergency risk communication CDCynergy (CD-ROM). Centers for disease control and prevention, US department of health and human services.

Tan, A. S., Lee, C. J., \& Chae, J. (2015). Exposure to health (mis) information: Lagged effects on young adults' health behaviors and potential pathways. Journal of Communication, 65, 674-698. doi:10.1080/10410236.2017.1331312

Tandoc Jr., E. C., Lim, Z. W., \& Ling, R. (2018). Defining “Fake News.” Digital Journalism, 6(2), 137-153. doi:10.1080/21670811.2017.1360143

Thelwall, M., \& Stuart, D. (2007). RUOK? Blogging communication technologies during crises. Journal of Computer-Mediated Communication, 12, 523-548. doi:10.1111/j.1083-6101.2007.00336.x

Tully, M., Vraga, E. K., \& Bode, L. (2019). Designing and testing news literacy messages for social media. Mass Communication and Society, 1-25. doi:10.1080/15205436.2019.1604970

Van der Meer, T. G. L. A., \& Jin, Y. (2019). Seeking formula for misinformation treatment in public health crises: The effects of corrective information type and source. Health Communication, 35(5), 560575 doi: 10.1080/10410236.2019.1573295

Wardle, C, (2017). Fake news. It's complicated. First Draft. Retrieved January 22, 2019 from https://medium.com/1st-draft/fake-news-its-complicated-d0f773766c79

\section{Funding}

This work was supported by a VENI grant from the Netherlands Organization for Scientific Research (NWO) under Grant number: 016.Veni.195.067

\section{Competing interests}

There are no conflicts of interests associated with this submission

\section{Ethics}

The research protocol, tools and measures were approved by the university's ethics committee All human subjects provided informed consent, and were told that they could leave the survey at any time without consequences. All data were stored and analyzed in compliance with the GDPR laws. Gender categories were predefined by the researchers, but participants were free to select 'other' if they did not want to classify themselves within the binary (male/female) category used. 


\section{Copyright}

This is an open access article distributed under the terms of the Creative Commons Attribution License, which permits unrestricted use, distribution, and reproduction in any medium, provided that the original author and source are properly credited.

\section{Data Availability}

Data is available via the following link https://osf.io/3kjge/ 
Appendix A - Sample composition and measurement of survey items

On March 19, 2020, the survey was conducted within four countries that were in mostly similar stages of the pandemic - the US, UK, Netherlands, and Germany. Multiple cases of COVID-19 infection and deaths were reported and governments started to implement public-health measures that restricted economic and public life. Even though the overall number of confirmed cases and deaths differed across the four settings, they were less severely hit than some other countries (Italy, Spain), and there were no issues of exceeded capacity in ICUs. Table A1. provides the descriptive information for each sample per country. Table A2. details the measurement of all variables included in this study. Quotes were set to resemble national variation in terms of demographic characteristics. We relied on the services of Dynata, a recruitment company that uses mixed databases (i.e., developed by partner companies) and invites respondents via email (voluntary opt-in lists).

Table A1. Sample composition per country

\begin{tabular}{llllll}
\hline & & NLD & US & UK & GER \\
\hline $\mathrm{N}$ & 330 & 339 & 326 & 326 \\
Age & & $42.52(13.27)$ & $49.19(14.50)$ & $47.54(12.21)$ & $44.42(13.47)$ \\
Gender & Women & 182 & 245 & 172 & 162 \\
& Men & 148 & 90 & 154 & 163 \\
& Other & 0 & 4 & 0 & 1 \\
Income & Low & 52 & 63 & 63 & 106 \\
& Medium & 134 & 190 & 153 & 135 \\
& High & 146 & 86 & 110 & 85 \\
\hline
\end{tabular}

Table A2. Measurements

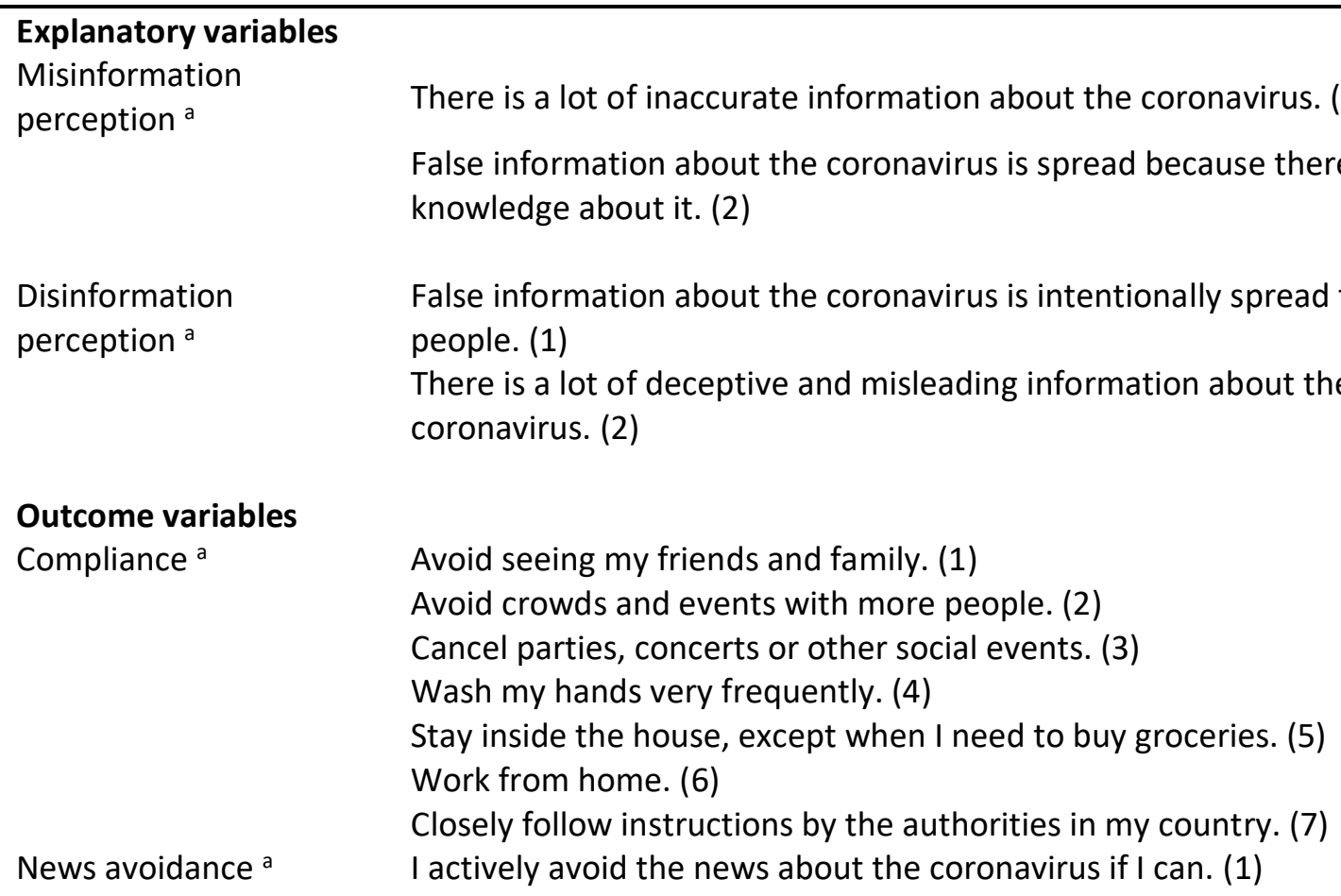




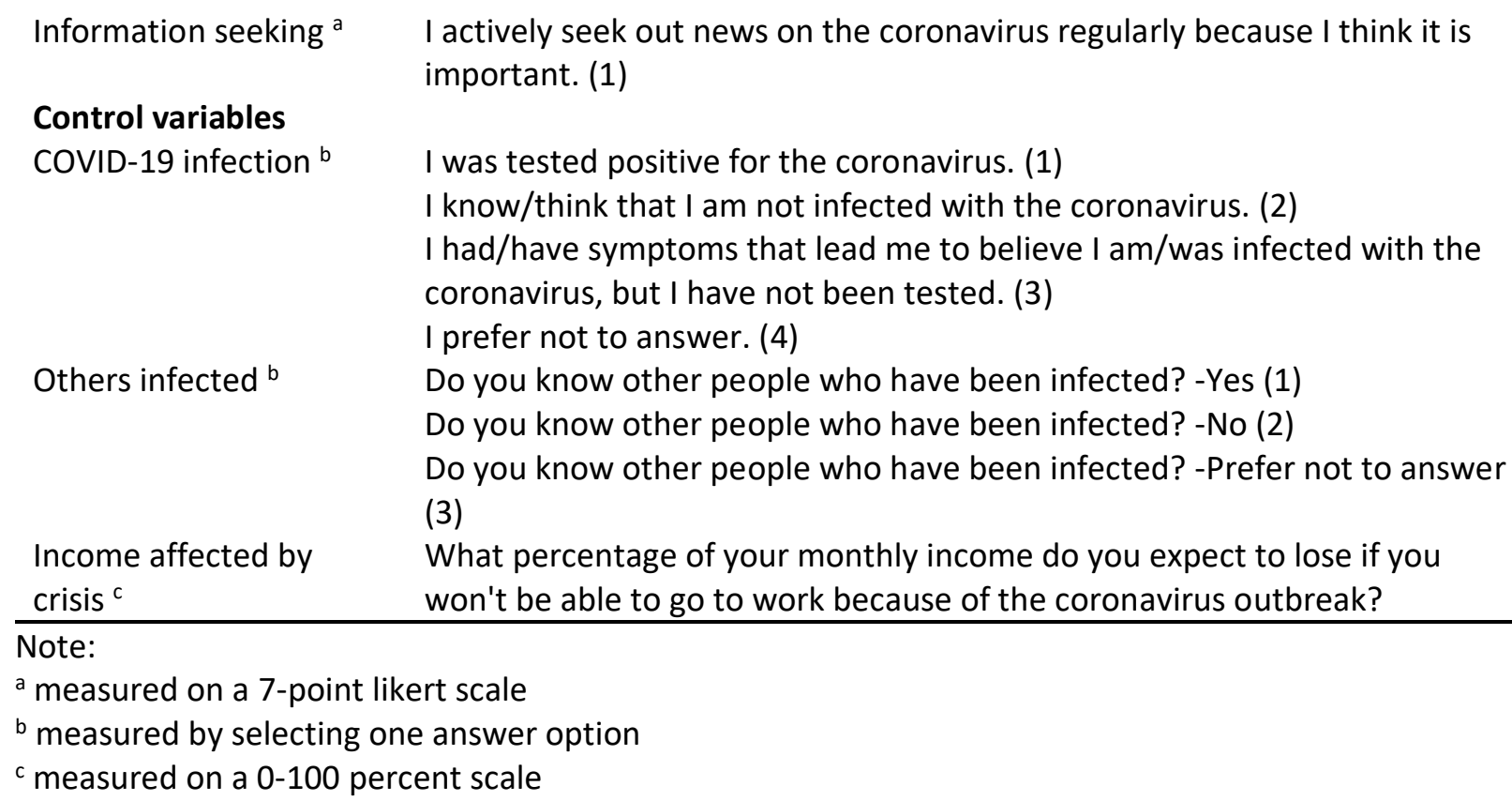


Appendix B - Full results tables for all countries

Table B1. Willingness to comply predicted by levels of perceived mis- and disinformation, specified per country

\begin{tabular}{|c|c|c|c|c|}
\hline Country & NLD & US & UK & GER \\
\hline & Compliance & Compliance & Compliance & Compliance \\
\hline Misinformation & $0.13^{*}(0.06)$ & $0.37^{* * *}(0.07)$ & $0.25^{* * *}(0.07)$ & $0.28^{* * *}(0.06)$ \\
\hline Disinformation & $-0.05(0.07)$ & $-0.06(0.06)$ & $-0.22^{* * *}(0.06)$ & $0.08(0.06)$ \\
\hline Gender (male) & $-0.42^{* * *}(0.12)$ & $-0.45^{* *}(0.16)$ & $-0.44^{* * *}(0.13)$ & $-0.20^{\dagger}(0.12)$ \\
\hline Age & $-0.00(0.00)$ & $-0.00(0.00)$ & $-0.00(0.00)$ & $-0.00(0.00)$ \\
\hline $\begin{array}{l}\text { Left-right } \\
\text { ideology }\end{array}$ & $0.03(0.03)$ & $0.03(0.02)$ & $-0.04(0.03)$ & $-0.04(0.03)$ \\
\hline Education & $0.03(0.08)$ & $0.11(0.11)$ & $0.13(0.09)$ & $0.14^{\dagger}(0.08)$ \\
\hline $\begin{array}{l}\text { COVID-19 } \\
\text { infection } \\
\text { (expecting } \\
\text { contamination)a }\end{array}$ & $0.00(0.00)$ & $0.50(0.98)$ & $0.00(0.00)$ & $-0.05(0.68)$ \\
\hline $\begin{array}{l}\text { COVID-19 } \\
\text { infection } \\
\text { (expecting no } \\
\text { contamination) } \\
\text { COVID-19 }\end{array}$ & $-0.08(0.18)$ & $0.86(0.92)$ & $-0.30(0.24)$ & $0.63(0.62)$ \\
\hline $\begin{array}{l}\text { infection (prefer } \\
\text { not to answer) }\end{array}$ & $-0.88^{\dagger}(0.45)$ & $0.02(0.95)$ & $-0.62(0.42)$ & $-0.11(0.86)$ \\
\hline $\begin{array}{l}\text { Others infected } \\
(\mathrm{No})^{\mathrm{b}}\end{array}$ & $-0.18(0.17)$ & $-0.45(0.36)$ & $0.34(0.23)$ & $0.10(0.27)$ \\
\hline $\begin{array}{l}\text { Others infected } \\
\text { (prefer not to } \\
\text { answer) }\end{array}$ & $-1.43^{*}(0.69)$ & $-1.57^{* *}(0.55)$ & $-0.33(0.66)$ & $-0.44(0.87)$ \\
\hline $\begin{array}{l}\text { Income affected } \\
\text { by crisis }\end{array}$ & $-0.00(0.00)$ & $-0.00(0.00)$ & $-0.00(0.00)$ & $-0.01^{* *}(0.00)$ \\
\hline Constant & $5.78^{* * *}(0.39)$ & $3.59^{* * *}(0.98)$ & $5.90^{* * *}(0.50)$ & $3.91^{* * *}(0.71)$ \\
\hline$N$ & 330 & 339 & 326 & 326 \\
\hline
\end{tabular}

Note: Cells contain unstandardized regression coefficients, standard errors in parentheses

$+p<0.10, * p<0.05, * * p<0.01, * * * p<0.001$

a reference category: I was tested positive for COVID-19

${ }^{b}$ reference category: Others I know are infected by COVID-19

${ }^{c}$ reference category: The Netherlands 
Table B2. News avoidances predicted by levels of perceived mis- and disinformation, specified per country

\begin{tabular}{|c|c|c|c|c|}
\hline Country & NLD & US & UK & GER \\
\hline & News avoidance & News avoidance & News avoidance & News avoidance \\
\hline Misinformation & $-0.17^{\dagger}(0.09)$ & $-0.11(0.10)$ & $-0.07(0.10)$ & $-0.04(0.10)$ \\
\hline Disinformation & $0.30^{* *}(0.10)$ & $0.27^{* *}(0.09)$ & $0.32^{* * *}(0.09)$ & $0.16^{+}(0.09)$ \\
\hline Gender (male) & $0.02(0.17)$ & $0.23(0.22)$ & $-0.15(0.20)$ & $-0.23(0.18)$ \\
\hline Age & $0.00(0.00)$ & $0.00(0.00)$ & $-0.00(0.00)$ & $-0.00^{*}(0.00)$ \\
\hline $\begin{array}{l}\text { Left-right } \\
\text { ideology }\end{array}$ & $0.00(0.04)$ & $0.09^{* *}(0.03)$ & $-0.00(0.05)$ & $0.13^{* *}(0.05)$ \\
\hline Education & $0.05(0.12)$ & $-0.19(0.15)$ & $0.18(0.14)$ & $-0.09(0.12)$ \\
\hline COVID-19 & & & & \\
\hline $\begin{array}{l}\text { infection } \\
\text { (expecting }^{\text {contamination) }}{ }^{\mathrm{a}}\end{array}$ & $0.00(0.00)$ & $0.65(1.33)$ & $0.00(0.00)$ & $0.03(1.03)$ \\
\hline COVID-19 & & & & \\
\hline $\begin{array}{l}\text { infection } \\
\text { (expecting no } \\
\text { contamination) }^{\mathrm{a}}\end{array}$ & $0.20(0.27)$ & $0.62(1.25)$ & $0.91^{*}(0.36)$ & $-0.50(0.94)$ \\
\hline $\begin{array}{l}\text { COVID-19 } \\
\text { infection (prefer } \\
\text { not to answer) }\end{array}$ & $0.86(0.66)$ & $0.54(1.29)$ & $2.19^{* * *}(0.65)$ & $1.05(1.31)$ \\
\hline $\begin{array}{l}\text { Others infected } \\
(\mathrm{No})^{\mathrm{b}}\end{array}$ & $0.47^{+}(0.24)$ & $-1.51^{* *}(0.49)$ & $-0.80^{*}(0.35)$ & $-0.23(0.40)$ \\
\hline $\begin{array}{l}\text { Others infected } \\
\text { (prefer not to } \\
\text { answer) }\end{array}$ & $-0.49(1.01)$ & $-1.23^{+}(0.74)$ & $-0.85(1.01)$ & $-0.72(1.32)$ \\
\hline $\begin{array}{l}\text { Income affected } \\
\text { by crisis }\end{array}$ & $0.00(0.00)$ & $0.00(0.00)$ & $0.00(0.00)$ & $0.01^{*}(0.00)$ \\
\hline Constant & $1.07^{+}(0.57)$ & $2.53^{+}(1.33)$ & $1.08(0.76)$ & $1.87^{+}(1.07)$ \\
\hline$N$ & 330 & 339 & 326 & 326 \\
\hline \multicolumn{5}{|c|}{$\begin{array}{l}\text { Note: Cells contain unstandardized regression coefficients, sta } \\
\text { tp }<0.10, * p<0.05, * * p<0.01, * * * p<0.001 \\
\text { a reference category: I was tested positive for COVID-19 } \\
\text { b reference category: Others I know are infected by COVID-19 } \\
\text { c reference category: The Netherlands }\end{array}$} \\
\hline
\end{tabular}


Table B3. Information seeking predicted by levels of perceived mis- and disinformation, specified per country

\begin{tabular}{|c|c|c|c|c|}
\hline Country & NLD & US & UK & GER \\
\hline & $\begin{array}{l}\text { Information } \\
\text { seeking }\end{array}$ & $\begin{array}{l}\text { Information } \\
\text { seeking }\end{array}$ & $\begin{array}{l}\text { Information } \\
\text { seeking }\end{array}$ & $\begin{array}{l}\text { Information } \\
\text { seeking }\end{array}$ \\
\hline Misinformation & $0.16(0.10)$ & $0.32^{* *}(0.10)$ & $0.22^{*}(0.11)$ & $0.07(0.11)$ \\
\hline Disinformation & $-0.12(0.11)$ & $-0.15^{\dagger}(0.09)$ & $-0.39^{* * *}(0.10)$ & $0.09(0.10)$ \\
\hline Gender (male) & $0.10(0.20)$ & $0.05(0.23)$ & $-0.08(0.20)$ & $0.25(0.19)$ \\
\hline Age & $-0.00(0.00)$ & $-0.00(0.00)$ & $-0.00(0.00)$ & $0.00(0.00)$ \\
\hline $\begin{array}{l}\text { Left-right } \\
\text { ideology }\end{array}$ & $-0.07(0.05)$ & $-0.02(0.03)$ & $0.01(0.05)$ & $-0.06(0.05)$ \\
\hline Education & $0.11(0.14)$ & $0.46^{* *}(0.15)$ & $0.03(0.14)$ & $0.08(0.13)$ \\
\hline $\begin{array}{l}\text { COVID-19 } \\
\text { infection } \\
\text { (expecting }^{\text {contamination) }}{ }^{\mathrm{a}}\end{array}$ & $0.00(0.00)$ & $0.85(1.39)$ & $0.00(0.00)$ & $0.51(1.13)$ \\
\hline $\begin{array}{l}\text { COVID-19 } \\
\text { infection } \\
\text { (expecting no }^{\text {contamination })^{\text {a }}} \\
\text { COVID-19 }\end{array}$ & $-0.30(0.31)$ & $0.42(1.30)$ & $-0.48(0.38)$ & $0.17(1.03)$ \\
\hline $\begin{array}{l}\text { infection (prefer } \\
\text { not to answer) }\end{array}$ & $-1.12(0.76)$ & $-0.26(1.34)$ & $-1.28^{\dagger}(0.68)$ & $-0.80(1.43)$ \\
\hline $\begin{array}{l}\text { Others infected } \\
(\mathrm{No})^{\mathrm{b}}\end{array}$ & $0.00()$. & $0.00()$. & $0.00()$. & $0.00()$. \\
\hline $\begin{array}{l}\text { Others infected } \\
\text { (prefer not to } \\
\text { answer) }\end{array}$ & $-0.50^{\dagger}(0.28)$ & $0.49(0.51)$ & $0.60(0.37)$ & $0.29(0.44)$ \\
\hline \multirow{2}{*}{$\begin{array}{l}\text { Income affected } \\
\text { by crisis }\end{array}$} & $-0.84(1.16)$ & $-0.14(0.77)$ & $0.19(1.06)$ & $-0.32(1.44)$ \\
\hline & $0.00(0.00)$ & $0.00(0.00)$ & $0.00(0.00)$ & $-0.00(0.00)$ \\
\hline Constant & $5.27^{* * *}(0.66)$ & $2.24(1.39)$ & $5.17^{* * *}(0.80)$ & $4.26^{* * *}(1.17)$ \\
\hline$N$ & 330 & 339 & 326 & 326 \\
\hline \multicolumn{5}{|c|}{$\begin{array}{l}\text { Note: Cells contain unstandardized regression coefficients, sta } \\
+p<0.10, * p<0.05, * * p<0.01, * * * p<0.001 \\
\text { a reference category: I was tested positive for COVID-19 } \\
\text { b reference category: Others I know are infected by COVID-19 } \\
\text { c reference category: The Netherlands }\end{array}$} \\
\hline
\end{tabular}


Appendix C - Result tables with dichotomous variable indicating whether respondents held a higher disinformation perception or misinformation perception about communication regarding COVID-19

Table C1. Willingness to comply, news avoidance, and intentional exposure predicted by whether respondents have higher disinformation perception than misinformation perception

\begin{tabular}{|c|c|c|c|}
\hline & Compliance & News avoidance & Information seeking \\
\hline $\begin{array}{l}\text { Higher disinformation } \\
\text { perception than } \\
\text { misinformation } \\
\text { perception }\end{array}$ & $-0.26^{* * *}(0.07)$ & $0.43^{* * *}(0.12)$ & $-0.28^{*}(0.13)$ \\
\hline Gender (male) & $-0.30^{* * *}(0.07)$ & $-0.20^{\dagger}(0.11)$ & $0.07(0.12)$ \\
\hline Age & $0.00(0.00)$ & $-0.00^{*}(0.00)$ & $0.00(0.00)$ \\
\hline Left-right ideology & $0.01(0.01)$ & $0.07^{* *}(0.02)$ & $-0.04(0.03)$ \\
\hline Education & $0.03(0.05)$ & $-0.07(0.07)$ & $0.14^{+}(0.08)$ \\
\hline $\begin{array}{l}\text { COVID-19 infection } \\
\text { (expecting }^{\text {contamination) }}\end{array}$ & $1.07^{+}(0.59)$ & $-0.81(0.95)$ & $0.63(1.02)$ \\
\hline $\begin{array}{l}\text { COVID-19 infection } \\
\text { (expecting no }^{\text {contamination) }}\end{array}$ & $1.03^{+}(0.58)$ & $-0.43(0.93)$ & $0.34(1.00)$ \\
\hline $\begin{array}{l}\text { COVID-19 infection } \\
\text { (prefer not to } \\
\text { answer) }^{\text {a }}\end{array}$ & $0.34(0.60)$ & $0.08(0.97)$ & $-0.29(1.05)$ \\
\hline Others infected (No $)^{b}$ & $-0.13(0.12)$ & $-0.13(0.19)$ & $0.02(0.21)$ \\
\hline $\begin{array}{l}\text { Others infected } \\
\text { (prefer not to } \\
\text { answer) }\end{array}$ & $-0.91^{* *}(0.35)$ & $-0.05(0.56)$ & $-0.62(0.61)$ \\
\hline $\begin{array}{l}\text { Income affected by } \\
\text { crisis }\end{array}$ & $-0.00(0.00)$ & $0.00^{* *}(0.00)$ & $0.00(0.00)$ \\
\hline Country (US) ${ }^{c}$ & $-0.04(0.10)$ & $0.12(0.16)$ & $0.21(0.17)$ \\
\hline Country (UK) & 0.07 (0.09) & $0.21(0.15)$ & $0.17(0.16)$ \\
\hline Country $(G E R)^{c}$ & $0.34^{* * *}(0.09)$ & $-0.05(0.15)$ & $0.69^{* * *}(0.16)$ \\
\hline Constant & $5.23^{* * *}(0.60)$ & $2.52^{* *}(0.96)$ & $4.44^{* * *}(1.04)$ \\
\hline$N$ & 919 & 919 & 919 \\
\hline
\end{tabular}

Note: Cells contain unstandardized regression coefficients, standard errors in parentheses $+\mathrm{p}<0.10, * \mathrm{p}<0.05, * * \mathrm{p}<0.01, * * * \mathrm{p}<0.001$

a reference category: I was tested positive for COVID-19

${ }^{b}$ reference category: Others I know are infected by COVID-19

${ }^{c}$ reference category: The Netherlands 